\title{
A Reflection on the Research Method and Exemplary Application to the College and University Rankings
}

\author{
Kiyoung Kim ${ }^{1, ~ *, ~ H y u n-M e o n g ~} \mathrm{Ju}^{2}$, Marium Khatun ${ }^{2}$ \\ ${ }^{1}$ The Legal Research Institute, College of Law, Chosun University, Kwang-ju, South Korea \\ ${ }^{2}$ The Legal Research Institute, Chosun University, Kwang-ju, South Korea
}

Email address:

kiyoungkim@chosun.ac.kr (K. Kim),Ek00769@chosun.ac.kr (H. M. Ju), marium@gmail.com (M. Khatun)

\section{To cite this article:}

Kiyoung Kim, Hyun-Meong Ju, Marium Khatun. A Reflection on the Research Method and Exemplary Application to the College and University Rankings. Education Journal. Vol. 4, No. 5, 2015, pp. 270-282. doi: 10.11648/j.edu.20150405.23

\begin{abstract}
It was a precious opportunity as a teacher and researcher that I had completed two research method classes with the peers of Laureate Education Inc. Since the generation of creative knowledge and meaningful contribution to the field is charged on the professional researcher, the classes are foundational, but unfortunately with less an attention by the scholars, and, if more problematically, even lack of courses for some graduate or training programs. Within this paper, I can be gladly reminiscent of the course learning, and can present a work of demonstration by employing the issues of global college rankings. In this article, my purpose is gone with three basic aims; (i) present the brief summary of my experience on the two method classes (ii) suggest a new perspective and mindset within the changing technology and post-modern transformation of society (iii) finally show two examples of mixed method involved with the global college rankings and provide a view for the students situated within the temporal boundary I had set forth.
\end{abstract}

Keywords: Researc Method, Qualitative Studies, Mixed Method, Data Collection, Data Analysis, College and University Rankings, Theory and Philosophy

\section{Introduction}

It had been a precious opportunity as a teacher and researcher that I have completed two research method classes with the peers of Laureate Education Inc. Since the generation of creative knowledge and meaningful contribution to the field is charged on the professional researcher, the classes are foundational, but unfortunately with less an attention with the scholars, and if more problematically lack of courses for some graduate or training programs. With this paper, I can be gladly reminiscent of the course learning, and can present a work of demonstration by employing the issues of global college rankings. Throughout this work, I may be indebted to the robust instruction or helpful insight and feedback with my peer participants. Generally, the kind of valuable terms and methodological debate had truly affected what is the responsibility of scientist, and especially on the qualitative method, how they highlight the theme or purpose as a social scientist in order to raise a voice of intact cultural group or deal with the phenomenological, narrative and case studies. All the ways through, we can see the science bull's watch as elaborated on what is verity and has social meaning. In this article, my purpose is gone with two basic aims (i) the brief summary of my experience on the two method classes (ii) suggest a new perspective and mindset within the changing technology and post-modern transformation of society (iii) finally present two examples of mixed method involved with the global college rankings and provide a view for the students situated within the temporal boundary I had set forth.

\section{Reflection on the Research Method}

\subsection{Introduction}

Through the classes, I have recognized a primacy and importance of research method as well as its variability to address the goals of researcher. The education and training session about this scholarly basics should enter a more weight of graduate education, particularly for the developing nations. Often researchers in this scope lack the formal hours of class to meditate on the research methodology. They rather acquire the skills and competence after they graduate and serve as a professor or professional researcher. Except for the natural science or engineering, this point seems to factor a 
relatively poor performance of those nations' researchers in the international context of social science and humanity studies. As a Korea-based scholar, this point seems to be complicated since Korea will no longer be a developing country in terms of world economy (Mills, W. C., 1959). Intellectually, however, I may not be definite if Korea can lead or influence the concerned of world, generally the circle of scholars in the specific fields (1959). The melting signs may seem gradually into the center of world and region when we bred a world renowned pop star, Psy and K-pop, commercially in the region as well as ambitiously in the Europe. An aboriginal scene of sweat labor could bring the industrialization of Korea in 1970's, and its consequence to bell the international society was demonstrated in the 1988's Seoul Olympic. For the new millennium, the cultural and intellectual advance can be Koreans', but with some care about the tendency. I may call the context as a "Korean fate of quintet (KFP: 70-80-10-60)." As said, the natural science, medicine or health and engineering sectors in the academy had been and will be a plane for good in terms of Korean share. It is highly dubious, however, if that could be true about the humanity and social science, which should be ameliorated until 2060. As this context fairly relates with my case as a researcher, the class of research theory and design is believed really challenging and ambitious in view of the personal aim. I suppose if the trained writer on these methods can produce an article of high scholarly impact as much cited as $P s y$ and viewed as many as 200 million people through the Y-tube. This context can be same with the scholars of similar states historically, economically, socially and politically. The classes on this purpose, I consider, is also helpful to the established scholars and authorities that we can philosophically retrospect the kind of our lifetime works.

\subsection{Self-Assess Your Current Research Mind-Set and Skills}

The classes will certainly be highly helpful to improve the research mind-sets and skills. First, it provided a good opportunity to eliminate a fear or ambiguities from lack of accurate knowledge about the methodology. We often name or talk about the research methods, but without a general exposure about the subject. That would be a strand to bring the fear or unsettlement on ambiguities. Second, the class systemically developed and enriched my understanding of research method and skills (Creswell, 2009). With the time for this course, we come to know a philosophical angle to support the research methods, theory and its construction, the ingredients of three basic methods, the ethics involved in the research as well as other useful issues (Reynold, 2007). It has been impressive to shape the worship of profession in the assignment about an NHS certificate. This worship did not stop there, but to inflame a curiosity of what is the research and its practice in the methodological aspect. We thankfully received a good system to increase of the research skills by processing weeks of experimental work covering the quantitative, qualitative, mixed and evaluation (Creswell, 2009). Third, the class seems not to finish in the personal context, but relays my interest into an adjacent area of disciplines. For example, we could learn the use of statistics or psychology, at least their basics, to realize a complete grasp concerning the quality of respective method (Patton, 1999). According to P. Serdyukov, a doctor is a carrier of high culture, expertise, and knowledge for their respective field of science. This statement can well corroborate with the view of habitus proposed by P. Bourdieu, and also comes lighted to explain the global status including Korea and other countries. Once I have pointed out the econo-political view of research profession, but that would be a particle though it might be essential for the pure materialists (Kim, 2015, 1). This aspect of profession anyhow seems to be interwoven from those elements of methodology in some extent of combination. Certainly the research can exploit the market and lead to the increase of demand economically in the higher or lesser extent from the perspectives. It, on the other, is related with the aspect of souls for decency and nobility. The laborers in the 1970's sweat shop of Korea now are led to entertain an innovative quality of K-pop or Y-tube classics. The researchers in Korea, perhaps as teamed with the policy makers, could bring the social change, and the invention of Y-tube, from the root efforts of research technicians, could realize such amazing habitus. The researchers of public administration and economy in Korea now implore on a high priority of creative economy as the national strategy, which we can acknowledge a positive sign of benefit.

\subsection{Evaluate a Relationship Between the Research and Social Change}

Concerning the relationship between the research and social change, I may state several points of relevance; (i) originality and application in the form of interplay (ii) comprehensiveness in the subjects of interplay (iii) strategic collaboration in the interest of interplay. First, the research pioneers the concern and curiosity, hence essentially creative or original (Kim, 2015-2; Parson, 2009). The great findings can be, and must be applied to improve our reality. Second, their interplay or relationship is comprehensive to take the researchers of specific discipline into any staunch of track in parallel and shared. For example, professors or researchers of economics devote their lifetime commission in parallel with the Federal Reserve. The legal scientists' usual work would arise from the cases and court opinions to be shared in their lifetime. The public policy students or researchers may get their concern or involvement related with the government or specific branches of public service. The educators may devote to the development of curriculum or method on college rankings that are concerned to be paired with the schools and universities. Probably we may well imagine its comprehensive picture in accordance with the scope of various governmental departments. Third, the contemporary practice of national or public organizations often views two facets as the kind of strategic alliance. This point is delicate if the researchers' ethics and standard are something different or sanctified. They need to be neutral and objective, and uphold the value of humanities. It is also highly capricious in its extent that some research will enjoy a buy-in, which 
means them productive in view of strategic alliance. The context will come in a comparison if the research were to be opposed or subject to public criticism, deemed less significant or as away from the strategic aspect.

\subsection{Plan Next Steps to Take in Becoming a Researcher and Scholar-Practitioner}

The plan to progress is to be guided so as to respond with the goals of researcher. The paradigm of scholar practitioner is really appreciable from the contemporary context of postmodern living. The lifetime concept of education and professional training are inevitable to improve and adapt with (Laureate Education, Inc., 2008). We are required, on the other, to prepare for the dissertation as a student or journal articles for the faculty or professional researchers. Hence, we are exposed to a multiple context of benefit to cross the work responsibility, learning, socialization and the research work. We can exploit the learning and knowledge to better perform our work duty as a scholar practitioner while the cumulative effect academically and from job experiences are believed to produce a high quality of research (2008). First, the partnership concept of dealing seems to yield a better result, which, I suppose, will be foundational to plan over the progress and academic success. We are a "scholar practitioner" - I mean in contrast "scholar in book" -- both to learn and teach, and the classes certainly would be an opportunity to refurbish the practical arms enabling to implement our value and scholarly conviction. We exchange ideas, valuable information and thoughts, not to be directed nor delivered in the unilateral lead of certain influence. This is an important assumption that may be embedded generally on the quality of graduate education. In some cases, the graduate students play as a teaching or research assistant, and their collaborative experience in the research labs often effects a lifetime alliance about the professional career of researcher. They are advised to rise beyond the attitudes as a student, but actively and positively engage as a scholarpractitioner (2008). Second, they need look into the research methods more in depth. Some higher level of methodology courses is essential to make a progress. Third, the law and public policy, through the years, had provoked my curiosity involving how to locate properly two disciplines in the transformative society. As a scholar practitioner, it will trouble much on time span since I had been interested in that name of specialty. A qualified status to be well-versed of research methods will facilitate my aim to look into both disciplines. The inquiry, "how do they excavate the knowledge to nurture their discipline?" will be basic and penetrates the different two into one string of commonality, i.e., methodology. Of course, the substantive issues will be dominant, but the hindsight only available for the methodologists will certainly happen to see the nature and essence of my interdisciplinary purpose. Fourth, the junior researchers may practice better by actively exploring a publication opportunity about their writing and collecting information about their studies and research method. This advice would allow the time to meditate on many basics, but must be foundational about the lifetime devotion as a researcher. It could help to share the information and experience with the peers so that will make the story of research profession as popular to know. The class of research theory seems to serve several purposes, and I feel much indebted respectfully from Creswell, Reynolds and the National Academy of Science. I have learnt much of information useful to understand the method itself, the nature of theory and its construction, and important lessons for the research professionals. Dr. DeParis' leadership and devotion to teaching had been impressive.

\section{A Thought on the Qualitative Method}

The kind of relationship or public tendency likely ascends as we are informed by the post-modernism, technology advancement and trajectory toward the informative society or creative economy (Husserl, 1931; Husserl, 1970; Rosenau, 1992). Now we seldom give a focus on the manufacturing, once the point of contest for the world economy. The kind of rhetoric, "world factory," is now the second title for the world economy, and the middle class within such income range perhaps would be less stimulating or likely approach dormant for the policy makers. They likely remain with them as main, but appear to be elusive with an expectation of same consequence in their thought or public process. That probably would not be wrong at least if we are simple and honest of economic aspect of their lives. The economy is powerful indeed-- and perhaps most urgent for humans -- if it is only field to enlist in the Nobel prize from the social science. The Thomson Reuter reports the SSCI statistics that separately classes from social science to deal with the Economics and Business along the general social science in total. Economically, we may safely defer to their assumption of middle class, perhaps common and generalized, if we are lovers of human. I do not argue for the use of qualitative research more widely for the public studies or suggest the cut of quantitative studies since the middle class is quite good at all (Scott, 1985). Humans are complex as we note in the Maslow's and we draw the data from the subjects in the qualitative method. We had got through the data collection and their analysis is staged somewhere, which obviously is very important to elevate the research plan. While humans are complex, only way to collect the data stems from his or her expression, hence, the kinds of occurrences, i.e., observation and interviews, documents (Creswell, 2013; Strauss, 1987). While man may not be exactly the expression of his or her statement, the coding lesson generally highlights such importance of "significant statement" to understand and analyze the data (Kvale, 2006). In the KTV, I had a moment of fantasia that one policy can create such significant words and statements not only from the interviewees and but also from the producers. To say, the title tears with impressive words, "Faith of Sons and Daughters," which seemingly is effective in struggling with the growing criticism as compared with the unemployment rate of young college graduates. The statements from the interviewees are 
capturing indeed with one aged male, 68 years old, who has no job expressing the savory support of small money in his later life. He seems still robust to work in the construction site, but the age actually impedes to turn away every opportunity for earned work. The statutory retirement age or pension plan of nations can be the work of "quantitative researcher," but must be inadequate for this person in my observation and according to his statement. Next hours shortly, the acting prime minister and head of business association featured in the press meeting that announced the policy programs and basic direction to improve the unemployment problem of young generations. Actually they learn and would be best to craft various policy measures. They would be ombudsman to report and assess as well as rule that are most needed of and exposed to the creative knowledge beyond the textbooks. In other words, the kind of case studies and grounded theory would likely work, and must be necessary for them as well as the government, one of biggest employers within the nation and perhaps major employer of professional researchers. While conducting a qualitative research as one of important instruments to staff the knowledge of government in the US - gradually within the context of Korea and other nations -- we need to have a thought why the research findings are seldom adopted to enforce. On the progress of my meditation, I also come to wake up if two persons with 100,000 dollars a year as their income are absolutely same deserving a good livelihood award and what are differences between top GDP country per capita and "perfect" or "graceful" from the words of interviewees collected from the research project dealing with the middle income earners of the top nation (Patton, 2002). Once we had been about the extended use of qualitative method in the studies of US government, and the kind of tendency has increasingly emerged over time in Korea. The newspapers highlight the importance of story-telling or episode relating with the public policy of government. The entitlements of aged people had been implemented last year, a hyperbole to be fought in the national assembly as concerned of the fiscal feasibility and social justice along the increasing restructuring into the aging society. Korean cable TV channels are in wide coverage and one of them, named $\mathrm{KTV}$, deals with the specialty of national policy. In one program aired yesterday, several aged people had featured and gave their narrative or words of graceful experience for the provision of entitlements. The amount is as small as 200 dollars a month, but had impacted likely astronomically for the poor and aged persons. The administrators or policy makers would learn during the course of their official duty. It is their trait, and most vigil than any other commoners. The top managers in the nation-owned enterprises may reflect like a person in the temple stay, one learning process on meditation. A tedious head of department may shame with his small of public activities that he likes to read and learn humans or community and wisdom for his responsibility (Patton, 2002). Most aids would be received from his working horses in the active rank and files that he would rather be enthralled as philosophical, humanistic, and communitarian than specifics. The learning occurs and essentially undergirds the contemporary society. The tendency is more impressive that the congressmen or policy makers in the executive are in the vortex of that reality. They would also be creators -- at least in the Korean context, as we know from Y.S. Kim in the 1990's, announcing that now is the age of life-time learning. It likely shows how we are related among another. Above all, the importance of their learning lies in the fact that it is not merely cultural or the kind of personal enrichment. It also is not such personal if we gird the ignorant or absent minded congressmen. It is crucially trusted with the paradigm of deliberative democracy. They have to shape their competence and be required to come with the exposure to the humans and community (Saldaña, 2011). The reelection possibility would be one motivating factor to push them to learn and to have awareness that we see them to be politically responsible. It was cited in the recent Korean source that Obama had the character of policy wonk, who would be an avid of every aspect of policy issues and agendas. This is no surprise at all when we consider his role and responsibility. Needless to illustrate the "marginalized and greatest approach" or "purposeful sampling" in the qualitative studies, the contrast often is quite useful to create the views or frames of social issues. The poverty and superrich would be one frame embedded with the intellectuals along the growth rate of economy. The kind of frame is also an avenue to testify the effect of policy programs or project as we see in the aged persons featuring in the KTV. It also demonstrates a continuing relevance with the lifetime learning that humans and community are inseparable or subjects of which politicians are fated.

\section{The Data Analysis}

The data analysis technique is constantly evolving, not a static repository with typical methods. ${ }^{1}$ For example, Eaves suggests that the synthesis approach in the ground theory could increase understanding and enhance the quality of GT data analysis techniques (2012). While he noted that there has been a steady rise in the number of published research reports that use the GT method, he viewed that the current method in prevailing use lacks the clarity and inconsistencies. It is needless to mention in the field of natural science that researchers reported a new data analysis technique to rapidly identify the region of stable crack growth in crack tip opening angle (CTOA) testing of a modified double cantilever beam (Hashemi, Dastani, Sadri, 2013). The method could replace for the visual analysis of the individual photographs, which is tedious and rather lengthy. This implies that the data analysis is considered in terms of cost and convenience of researchers in common with both

1 For example, the fifteen methods may be suggested, i.e., typology, taxonomy, constant comparison, analytic induction, logical analysis or matrix analysis, quasi-statistics, event analysis or microanalysis, Metaphorical analysis, domain analysis, hermeneutical analysis, discourse analysis, discourse analysis, semiotics, content analysis, phenomenology or heuristic analysis, and narrative analysis. 
sciences. The data analysis technique also occurs involved with the literature review which represents the most important step of the research process in all three methods of social science. Boote and Beile expounded, "A thorough, sophisticated literature review is the foundation and inspiration for substantial and useful research." Therefore it is the kind of crucial concern of qualitative researchers how to construct a research synthesis aptly. In this context, four types of data in connection with the five qualitative data analysis techniques have been studied by three scholars, who drew on any most optimally rigorous way concerned of literature review (Onwuegbuzie, Leech, Collins, 2012). This study implies the relevance of data analysis technique with the literature review, which are inseparable, but into the research synthesis and on iterative process among the data and literature.

\section{Techniques of Qualitative Data Analysis}

According to Merrill et al, the techniques of qualitative data analysis are commonly shared among the approaches, which includes (i) documentation of the data and the process of data collection (ii) organization/categorization of the data into concepts (iii) connection of the data to show how one concept may influence another (iv) corroboration / legitimization, by evaluating alternative explanations, disconfirming evidence, and searching for negative cases (v) representing the account (reporting the findings) (2000). It is grossly intertwined with the collection and documentation of data, and it is important to note that the data analysis actually begins at the time of observation, interviewing or both. The researchers always get the data as central for validity and reliability of research that analytic process bases by simply hinging on the notes or transcripts with repeated reading (Kvale, 2006). The concept could be the kind of oasis sublimating the raw data into a cohesive scientific message that he or she creates by organizing and categorizing the data into concepts. Important is the need to develop the relationship or hierarchy of concept that is essential to structure his theme and produce a due density of scholarly presentation as normalized to the intelligence of audience, perhaps, supervisor of dissertation or referees and peers of professional journal. In this process, they may use the concept map. Then the positive steering from the raw data into major profile of assertions would likely be completed that the researchers will make an enhancement of theme with corroboration and legitimization (2000). He or she evaluates alternative explanations or discuss disconfirming evidence and may search for negative cases. This may simply show the process to deal with the data, but would be most important technique to be minded. There will be a tack of collected data in the form of observed results or interview transcriptions as well as public or private documents. The photos and video materials may not be planned at some stage, but the possibility of inclusion is not unlikely along the development of theme. We have surveyed the benefit of NVivo, and the data storage and analysis would obviously be facilitated with such modern technology. At the center of dynamism do the codes, themes or concepts underlie that important statement of participants should not be missed or gone as unattended. Weekly team meetings among the key participants and researcher can be arranged that keys on the progress of research including the evaluation and analysis of data. As once stated, documentation from the interviews and observations of sites, photos, and videos are a major form of data source to represent the empiricism that requires a care and focus for management and analysis. Miles and Huberman proposed useful tools named the summary contact form that shows the flow model of qualitative data analysis components, which are applicable to the various research plans (Creswell, 2013). For example, we may prepare the contact summary form structured with the flow of relevant questions or points of consideration i.e., (i) what were the main issues or themes that struck us in this contact (ii) summarize the information we got (or failed to get) on each of the target questions we had for this contact (iii) anything else that struck us as salient, interesting, illuminating or important in this contact (iv) what new (or remaining) target questions do we have in considering the next contact with this site (Merrill et al, 2000).

In consideration of analysis technique, a considerable amount of data may be produced in the aboriginal language, and we may think how the translation into English language is viewed. It would be no seldom for researchers given the scope of deals in the international case studies or ethnography and narrative studies of significant person. The website of Johns Hopkins University provides a tip on this interest (2015). At first, it needs to be determined whether to translate or not, in which the researchers consider various factors, such as logistical, ${ }^{2}$ validity, ${ }^{3}$ customer, ownership and control, and implicit or unintended message from the original data (2015). The researcher also considers the benefit and drawback of translation. For example, the researcher may plan to conduct the data collection in English which obscures the issue originally, and the multisites investigation often allow to have a common language for analysis. Most of all, he has to know that the interpretation is very time consuming. The common view is that the translation leads the raw data or theme to be too literal and insipid, which may, in some case, be inaccurate as differs from the original nuance or authentication of phenomenon. The translation of raw data into language within the process of analysis and publication also entails a delicate problem of privacy or indecency with no use at all. In that case the research may use "Do Not Translate List," which includes, for example, words for friend or friendship, words for HIV, or terms referring to the act of sexual

\footnotetext{
2 For example, he inquires of how much time it will take.

3 For example, he considers how much time it will take, if the translation is accurate, if the original meaning is distorted, or if anything is omitted?
} 
intercourse (2015).

\section{Blending and Adapting}

As per the qualitative method, it seems to me that the challenges and subtleties arise from two properties of qualitative studies. That is, the qualitative researcher has to play as an unobtrusive observer in the data collection stage, and should be a good surveyor who competently and persuasively triangulates the findings. The issue of triangulation occurs in dimensions and relating with the enhancement of credibility as we are aware. In other words, it may be exercised involved with the stages of qualitative research, i.e., among the data collection, analysis and writeup as well as different methods, such between quantitative and qualitative methods. To say, the qualitative findings can improve the trustworthiness and credibility by triangulating their findings with the empirical evidence gained from the quantitative studies. Triangulation is the kind of properties intrinsic with the humans and universe provided if they are evolutionary or fluid on one hand and stagnant on the other. ${ }^{4}$ Hence, we can be assumed to have a better understanding by blending or adapting the stories generated from both sources. Patton guides four kinds of analytical triangulation which covers triangulation of qualitative sources, mixed or qualitative-quantitative methods triangulation, analyst triangulation and theory/perspectives triangulation (2002). Creswell also depicts a simple, but capturing three elements in the diagram showing three elements are intersected to produce the qualitative knowledge (2013). In this showing, the world views, assumptions, theories are one sector while the qualitative researchers also are responsible for the other two, say, research design and approaches to inquiry. All the elements would be evolutionary or fluid, but stagnated commonly, and varying with the different degree. For example, the assumptions, research design and approaches to inquiry would be more evolutionary or fluid than others seen more stagnated. The blending or adaptation is the kind of art in which the qualitative researchers are to be measured and creativity or value competes for the quality piece of articles or books. Given the researcher himself would be a learner through his project, it might be the zone of proximal development (ZPD) as if one junior researcher defined, "the distance between the actual developmental level as determined by independent problem solving and the level of potential development as determined through problem solving under...guidance or in collaboration with more (Heinze, 2008, p.3)." Along our understanding of qualitative method, it likely would be felt to us that we experience many blind alleys, dead ends and treacherous terrains (Gay, 2000). The blending and adaptation would incur on these challenges and possible incongruity so as to be destined within the treacherous terrains. We have seen the importance of

4 This kind of strand may be ideated, for example, the most recent NRC studies on the assessment of doctoral programs that the frame was developed within two dimensions, regression quality and survey quality. heuristic process within the learning and research, and the blending or adaptation would be some kind of culminating stage that turns the story into conclusion (Atkinson, Coffey, Delamont, 2003). While the blending or adaptation is presumed of empirical data collected, this never denies the importance of qualitative strands. As we learn, purpose guides the analysis of data, and well prepared mind is necessary to orient and define the quality and more refined dealings of qualitative research. The focus and lens of analysis within the subjective minds would not be an evil, and the action research or voice for the minority group to increases the awareness of audience are popular in this method. As Pascal preached, the zeal and knowledge would be the quality with which the archaic of new knowledge emerges and the blending or adapting is practiced by the researcher (Patton, 2002). ${ }^{5}$ In consideration of blending or adaptation as the kind of creative final touch for the work, the qualitative studies, as we know, has a distinct aura or trait that had been argued over hundreds of pages in the textbook. It is truly discriminative to make the studies qualitative indeed. As we see the post-modern reality of contemporaries, whether marginalized or super-marked, both turn to be qualitative (Holmes, 1962). The exchange of public discourse now transcends the general and often overwhelming proposition based on the quantified data, but the contexts, stories or themes can express more in-depth and be suited with the reality. For instance, the Smith College recognized that the faculty takes on new teaching challenges and viewed that they learn best from one another. With the difficulties of physical gathering of faculty and challenge of limited resources, they developed online series of case study modules with the participation of "blended faculty." "This corroborates with the suggestion of triangulation from the perspective by "multiple analysts" in Patton, and shows the contentious process to the collective intelligence which might be dialectic or teleological (2002). As we note, the collective intelligence is shared or group intelligence is formed that

\footnotetext{
5 Pascal, in the Pensees, illustrated four kinds of persons in the universe, who would have zeal without knowledge, knowledge without zeal, neither knowledge, nor zeal, both zeal and knowledge.

6 This might be seen superficial or just on the reality of ours without the quantitative verification. I consider if the qualitative research has a strength of depth or rich data from the field, I consider, on the other side, it may have the kind of superficiality, say, less on the description of general populace, but on the ethnos, cultural groups or minorities, which, however, would be realistic and cultural. The context likely revives the embedded dichotomy from the age of Platonic discourse, what social psychologists call "the principle of superficiality versus depth." For example, Lyotard challenged the Platonic view of a true meaning hidden behind surface. He instead insisted that sense manifestations had their own reality which necessarily impacted upon the general world view. I feel that his attribution to a "theatrical world view" and the "purely verbal order of intelligibility" can be seen the quality of knowledge generated from the quantitative studies. In other words, it would be hyped to rule and be ordained with some textual order of verbs, and he sends the message that the postmodernist may work on the apparent reality or distinct cultural group. The blending or qualitative adaptation may be qualitative or even purposive in some aspect that, nevertheless, would be zone of art and skills, values and valorization of critical thought on the part of researchers. This view can also be shared with the deconstructionists, who have increasingly sought to undo the depth/surface hierarchy, proposing in ironic style that superficiality is as deep as depth.
} 
emerges from the collaboration, collective efforts, and competition of many individuals and appears in consensus decision making. Creswell discussed the concluding stage of qualitative research, and illustrated the importance of blending or adaptation between the contents and methodology (2013). Therefore, it often occurs in two contexts in which the research can be more credible or confirmable with analytical triangulation and where the concluding stage led to conclusion requires for sublimation from the contents and methods.

\section{Application Example}

The following two Exhibits had been prepared in view of the principles and practicalities exchanged over the years of peer communication and data collection within the methodology classes. They had been generated from the longitudinal observations and by applying the data analysis techniques.

\section{Exhibit I}

The academic strengths of institution were based on the NRC data that were released in 2010 and 1996. The data basically purported to provide the assessment of quality for the doctoral programs, but is considered to show the variety and commitment of institutions to teach and research. Given the specific ranks essentially came with the quality of doctorate programs, the number of programs evaluated and ranked indicates the width and depth of institutional performance as a whole. Often the institutions came with the first impression about the scope of offerings with the three levels of degree programs, such as 150 programs for bachelors, 100 programs for masters, and 60 programs for the doctorate. That is the first and last lens to look at the educational institutions, and is considered as foremost at the basic and most attribute. This is despite such popular perception from the rampant ranking schemes nationally and globally. It is related with the very basic function and role of institutions and shows the total level of intelligence and contribution which turns on the benefit of students eventually. Since the college education, especially at the undergraduate level, is liberal and interdisciplinary - of course, interdisciplinary nature had gradually come stressed with the graduate education - this aspect of institutions is viewed in emphasis. The problem is how to draw the pertinent information to measure this reality. Besides the mere number of programs with the university website, the number of NRC rated programs would inform us more properly that there was set a practical limitations with the least number of doctorates at five and fits within the purpose of national scheme of doctoral studies. It shows the operability of programs and its academic meaning that was assigned most of value to measure the whole populace of institutions, say, faculty, undergraduate, masters and doctorates. It is unique with the educational administration of US, but in some cases over the global jurisdictions, the nations, such as Korea, would have a similar data compiled by the ministry of education. For example, we can confirm that Minnesota comes second with 74 programs rated or UC Berkeley with 52 programs for the tenth place, while Seoul National University doctoral programs are officially acknowledged at 50 indications of doctoral field and Yonsei will come with 45 indications. In other cases, perhaps more liberal or private without this kind of data, the measure would be based on the webpage of institutions to be adjusted specifically with the contingencies of each nation or region.

Another indicator to measure the academic strengths of institution is to look into the publications of faculty. The number of publications, including the books and articles, indicate the quality of faculty and their commitment to the research. It could be measured as per capita of faculty or at gross that I applied the second method. The indicator shows the basic operation of academics for each institution, which could not be substituted with other applied point of angles, such as citation or major faculty awards. That is because such applied lens to view the institutions can lead us to the distortion heavily affected by the western dominance (Clifford \& Marcus, 1986). The assessment of college and university comes different from that of graduate or research degree programs. It was principally oriented to measure the effect of institutions on the undergraduate education. It comes vastly with the national context of educational aims that an immense focus on the number of contributions to the internationally prestigious journals and quality of professional communication of faculty, often critical in rating the rankings of the global universities should be neither such determinative nor highly discriminative. In other aspect we may also challenge that it can be some outdated privileges if many on-line journals now serve the need of India and China, most populated countries in the world - hence implications of universal college education-- and lend a space to exchange the scholarly views. We would not say that their educational service is defunct merely because they work based on the less prestigious journals, especially in terms of college education other than graduate level. The articles or books, far from the Nobel prizes or massive scholarly attractions with citations, can well be more precious and valuable in terms of college education. However, we cannot obtain a specific data with the integrity and system to measure any exactly the whole of institution's publications. Therefore, the Leiden ranking of publications were partly considered, which is based on some level of journals. In the case of US, 2007 studies from the Chronicle of Higher education was considered, in which the professor's publication was assessed on the basis of whole number of books and articles to yield the ranking of each programs. This type of data can be identified in other countries, of course, more probable in the developed countries. In the global scale, the indicators of Webometrics or institutional rankings compiled by the Spanish Academy can allow to refer to the similar nature of information in this concern. Although the rating agencies would request to offer the data for the basis of their assessment, the request often can 
possibly be neglected or responded unfaithfully at considerable extent as we may know previously from the rating scheme of Russian agencies. Then the ways of measure through the web search can provide any most comprehensive exposure of global institutions by the investigation of institution's website or on-line performance. It also is reflexive of the kind transformation sparked by the revolutionary change of electronic lives or professional communication. The international and national sources of information in this kind were combined and assessed to yield the final rankings of academic strength.

The other indicator to measure the academic strengths of institution stems from the consideration of research funding. As the money is most tangible evidence as a support of research, thus, very critical to measure the quality of research by the faculty. Besides the citation and faculty award, it could be more practical and competitive if money is an element. The weakness of this measure, however, is only covered in the planning stage of research, hence, input than output. In terms of graduate education, this indicator seems more highly relevant since the funding is essentially related with the recruitment of graduate students and common development as a professional researcher between the recruiting faculty and students (Gergen, 1994). Often the labs and groups can be formed on this basis to produce the kind of professional researchers with their nest. In terms of undergraduate education, it is seemingly less relevant, but I considered it still crucial since the funding competition becomes more intensified -- important point to view the strengths of faculty, who ultimately is responsible for the undergraduate students in the classroom. The measure of this indicator is not so challenging unlike other ones since the monetary terms are any more than universal at the global scale. And each nation certainly produces this type of data, and can be integral for the whole of global universities. For example, Harvard may come eighth in this statistics with a little less than 1.0 billion dollars, Oxford and Cambridge or University of Tokyo may rise at the place of 19 or 22 with 700 million or 600 million dollars. Since I had a temporal factor to provide a view for the graduates of colleges and universities from 1990 through 2010, my assessment of data is longitudinal in coverage over more than twenty years roughly coming with such period. It means, for example, that the University of Michigan and Berkeley in California may fare at second and eleventh place in the 2014 statistics of National Science Foundation. Besides, I can consider the unique university, UW-Madison over than twenty years compilation, which had fared within the range of top five institutions. In this way, the global rankings were compiled to yield the final ranking of this qualitative inquiry on the college and university rankings. In this concern, we can refer to the patent statistics and number of doctorates awarded, which also comes as same that is an important indicator for the graduate education, but comes less significant in terms of my basic perspective about the original role of university education. As the undergraduate populace is vast, we may properly be reflexive to contemplate what the colleges and universities are expected to play. The number of patent applications is related with the sense that the academic staffs are rather on the role of independent professional than educators. The number of awardees at doctorate level implies that the graduate education flourishes and thus more creative and research- oriented often led to the quality of faculty. This kind of indicators reflects the competitive capitalism or elite education to wake after the transformative global community (Giddens, 1991). Nonetheless, the theme in my case is what the original role of colleges and universities is and what it means for the universal education at the undergraduate level, most crucial stakeholders in the university (Hatch, 2002). As the faculty is a primary player to engineer the colleges and universities, they have a plenty of reason for the creative research and innovation, and preferably with the earnings and profits. Hence, it is necessary to consider this factor, but not in any gross share. One challenge in the context of college ranking is that it is only related with the engineering or applied natural science. Of course, we generally share in awareness that the massiveness in terms of the college and university population, including the students and faculty, is also characteristics of current college education and, hence, most important discriminating factor in the international college ranking. That is a part of reason that Caltech may come a top ahead Harvard occasionally or similar with the UC Berkeley. This pattern of institutions may well be compared with the kind of institutions, such as University of Chicago, Yale, NYU and Brown University. Between the overall citation statistics and that of humanity and social science available at 2008 Thomson Reuter, we can hint on this pattern, if the University of North Carolina comes as top class ahead of those institutions while it performed less strong in the citations of whole field. This aspect was considered as eclectic to evaluate the academic strengths of institution. The patent statistics have been compiled by concerned institutions, and not so challenging to confirm. Some institutional adjustment was made if the University of California comes first for the whole ten campus. Now we turn to see new Nobelists this year -- considered as top honors for the faculty, which is some part of factors for the university rankings. Therefore, it can be a source of competition for the sensitive universities who invited even for the temporal period of time to increase the international awareness or priority in the college rankings. In this sense, I have assigned more value with the number of alumni than the faculty members, who received the prize. Of course, it should be corroborating with my focus that there can we consider many of faculty awards much implicated with the context of national education, such as the national medals of science from the global jurisdictions (Guba, 1989).

Finally, the social aspect of institution based on the ranking of Facebook and Twitter needs to be considered that it is essentially intertwined with the intellectual aspect of college people beyond the social activities (1989). It also partly relates with the broad impact of institutions at global 
and national scale. I also viewed that the happiness concept of institutions is another important theme as we occasionally experience with the concerned people. Most importantly, the Facebook or Twitter now partly is the space of intellectual exchange of views and public opinions. A short comment in such social media from the influential scholars would be any echoing than hundreds-page books. We, of course, including the college people, can learn the essence of public issues and point of contentions. The informed people also could raise his view and opinions that was not feasible in the earlier years without such space. Along the transformation of our living mode, this aspect explains some part of institutional strength although little in share. Besides the direct ranking from Klout or others, the above Webometrics was utilized to compile the ranking, despite minimally, although it is neither immediate nor direct in terms of data attribute. There are some countries, of course, developed countries oftentimes, which compiled and published this type of data. The sources of this kind, globally and nationally, were considered to yield the final ranking.

(I) A Scope of Intelligence on the Offerings (30\%)

(II) A Scope of Intelligence on the Publications (20\%)

(III) A Quality of Research on the Research Funding, Patent and Number of Doctorates Awarded (20\%)

(IV) A Quality of Research on the Citations and Awards of Faculty (20\%)

(V) A New Mode of Intellectual and Social Exchange (10\%)

Table 1. A Rating of Global Universities

\begin{tabular}{lll}
\hline Rank & Institution & $\begin{array}{l}\text { Grade Point/Total of } \\
\text { Five Indicators }\end{array}$ \\
\hline 1 & University of Wisconsin-Madison & $(90.5)$ \\
2 & Harvard University & $(90.0)$ \\
3 & Stanford University & $(87.0)$ \\
4 & Massachusetts Institute of Technology & $(86.5)$ \\
4 & University of California-Berkeley & $(86.5)$ \\
4 & University of Michigan-Ann Arbor & $(86.5)$ \\
7 & Cambridge University & $(85.5)$ \\
7 & Oxford University & $(85.5)$ \\
9 & University of California-Los Angeles & $(83.0)$ \\
10 & Cal Tech & $(82.0)$ \\
11 & University of Minnesota & $(81.0)$ \\
11 & University of Pennsylvania & $(81.0)$ \\
13 & Cornell University & $(80.5)$ \\
14 & Columbia University & $(80.0)$ \\
15 & University College London & $(79.5)$ \\
15 & University of North Carolina & $(79.5)$ \\
15 & Yale University & $(79.5)$ \\
18 & Duke University & $(78.5)$ \\
19 & Johns Hopkins University & $(78.0)$ \\
20 & Northwestern University & $(78.0)$ \\
21 & University of California-San Diego & $(77.0)$ \\
23 & University of Washington-Seattle & $(76.5)$ \\
24 & New York University & $(76.0)$ \\
26 & University of Chicago & $(74.5)$ \\
& King's College London & $(74.5)$ \\
& University of British Columbia & $(72.5)$ \\
\hline
\end{tabular}

\begin{tabular}{lll}
\hline Rank & Institution & $\begin{array}{l}\text { Grade Point/Total of } \\
\text { Five Indicators }\end{array}$ \\
\hline 28 & University of Southern California & $(72.0)$ \\
28 & University of Tokyo & $(72.0)$ \\
28 & ETH-Zurich & $(72.0)$ \\
31 & University of Munich & $(71.0)$ \\
32 & University of Heidelberg & $(70.5)$ \\
33 & University of Illinois-Urbana C. & $(70.0)$ \\
33 & Complutense University of Madrid & $(70.0)$ \\
35 & University of Manchester & $(69.5)$ \\
36 & Seoul National University & $(69.0)$ \\
36 & University of Freiburg & $(69.0)$ \\
36 & Beijing University & $(69.0)$ \\
39 & University of Vienna & $(68.5)$ \\
40 & Moscow State University & $(68.0)$ \\
\hline
\end{tabular}

For the View of Graduates around 1993-2010 years

\section{Data Considered}

(I) Two NRC assessments (1996/2010) of research doctorate (Other similar nature of national sources)

(II) 2005-2013 Leiden ranking on the number of publications/2007 ranking from the Chronicle of Higher Education on the faculty productivity/SCImago institutional rankings (School's website and other similar nature of sources)

(III) Over 20 years NSF ranking of research funding and the number of doctorates awarded (Other similar nature of national sources)/National and international patent statistics

(IV) Wikipedia page for the Nobel recipients according to the institutional affiliation (School's webpage for the information of faculty awards)/ 2008 Thomson Reuter citation report of institutions

(V) Klout ranking of the colleges and universities on the social media and other similar nature of ranking sources on Twitter and Facebook / Partly with the Webometrics ranking of world universities

\section{Exhibit II}

I consider the methodology is the kind of cornerstone to yield a creative knowledge and thus definitive in forming the better world views. Let me kindly illustrate one example about the college selection of prospective international students who explored an option to study in the university other than US institutions. His major was one subject within the humanity and social sciences, and considered a pertinent guide available. Nowadays, many national and international source of college guides are publicly available, but his times would have scanty resources that provided a view for the prospective students. Among them, the Gourman report is one of popular ranking source around 1990's. The current sources, such as QS and other international rankings would just follow that report around some years later in time sequence. The US news and world report, one other national source, would uniquely be in parallel with the report in terms of time span of reporting. Both began reporting around 1970 's and 1980's while the current ranking sources were 
given a birth in the new millennium. The Gourman report was compiled and reported by Dr. Gourman, a counselor of Department of Education for the US government, and was published in the commercial version by the Princeton Review in 1997. My purpose here is twofold: (i) the qualitative method is one of best way to deeply look into the humans and universe; (ii) to provide the view of world best universities for the entering class around 1997 through 2003. Since the rating of institutions in this report is based on the academic curriculum, quality of teaching, research performance and campus facilities, i.e., mostly on the university libraries, it may dominantly be of quantitative piece except for some portions. Nevertheless, we can find the strand of qualitative approach with the separate deals for a major respective region, such as US and International sections. As we see, the most determinative query, in terms of research method discourse, would be, "what the researcher actually likes to know?" This query can lead to an adequate selection of methods between the three holds in practice, say, quantitative, qualitative, and mixed. Now we have vastly been bent on the quantitative method in generating an international ranking, such as measure of faculty publications and citations or so. It would be very kind to put some qualitative description of specific institution or special advice for the selection of colleges or subjects. The quantitative generalization, however, has a weakness to remain merely within the general description of populace. Furthermore, the quantitative factors may massively be on the field of engineering or natural science as the international rating agency itself is submissive. The fields are the kind of gold slot to generate the uniform scale of rating since the terms, versions and intelligence of those fields would be shared virtually at universal extent within the global professionals. From this attribute, the scale of measure can be uniform and persuasive for the stakeholders. This quality can no longer be held still strongly through the field of humanity and social science, in which the interest holders, such as prospective students in that area of study, would look for other more adequate guides or reference. Provided if the cultural, linguistic, and regional particulars are any more powerful factor that governs the area of such academics, their inquiry naturally turns on the qualitative nature (Huber \& Whelan, 1999; Henry, 1989). The Gourman report can be seen responsive to this need, and provides a good point of reference for the qualitative understanding in terms of world view. It separated a region leading to the quality of acculturation, realistic view of world politics and discourse, and some of linguistic adaptation, though simply imperfect. As we note, the keys of qualitative studies may be illustrated with the kind of purposeful sampling in the stage of data collection or identification of patterns through the data analysis.

The Gourman report corroborates with this trait of qualitative inquiries if it is regional and grouped with an adequate details of presentation. Therefore, the studies of Dr. Gourman can be viewed as the mixed approach at exact terminology, and the blending and adaptation are a critical process to form a world view of his research findings. In this respect, we can see the kind of intrinsic from the current international rankings, so that they are not detailed through the faculty, master and doctorate and truncated into one unit, while the national rankings, particularly with the US sources, are gone otherwise. You can find the ranking of undergraduate institutions in the United States and that of international institutions below, which I blended to produce the global rankings, for example, between the Academia de Paris and Princeton University. The rest of blending and adapting can be elaborated with the concerned institutions or people who were the students in that period of time. Besides the particulars of humanity and social science, I also should be concerned of small colleges, such as Amherst, Oberlin, and others from the US institutions. This aspect is also pertinent, for example, the small or Grand Ecoles from France and special schools, such as Berkeley College or Julliard and conservatories for the European music schools. These schools are particularly the kind of exteriors that deserve a qualitative rating with the in-depth studies. Therefore, the USNWR will separate the ratings between the doctoral level universities and colleges. The special rating agency also may rate their field, for example, LA source for the world drama schools, and the National Jurist for the most affordable-library law schools (Hurteau, Houle, Mongiat, 2009).

The blending and adapting exemplified between the Academie de Paris and Princeton University have been based on several points of consideration that eventually came tied for the top place of world - for example, (i) they are within a respective region that the liberal and social intelligence originated and now flourishes -- this quality was reflected in one case that the national research centers, such as CNRS, Chinese or Russian Academy, play a pivotal role leading their intelligence and understanding of the world so as to be rated in the SCImago (ii) Paris, the original state of modern university system traced back to early of $13^{\text {th }}$ century, and Princeton university for the national identity of United States (iii) besides the Gourman ranking, the institutions contributed to the world civilization massively over the humanity and social science and via production of Nobelists (iv) I considered the balance of power, the terms of international politics, through the weighing of global intelligence on equal footing - the view is the kind of art, as blended or adapted with uni/bi/multi-polarity, with the political scientists as if it would be with the qualitative researchers who rate the two distinct pans of intelligence, say, continental and US (Natioanl Academy of Science, 2000; Marty \& Appleby, 1993; Koro-Ljungberg \& Greckhamer, 2005). The qualitative researcher also does a best practice to identify the pattern of data, which could be applied to the data analysis. For example, the universities or Ecoles in Paris generally would arise from the common leverage as we note in Parisien or numbered name of universities, and are expected of public concept concerning the pattern of academics, common interchange and uniform supervision of doctoral studies with the Sorbonne scholars, as well as a number of specialized 
Ecoles under the title of Academie de Paris (Amstrong, Gosling, Weinman, Marteau, 1997; Carter, 1993). ${ }^{7}$ It is useful to consider one institution, CEDS Paris -- a small graduate oriented institution, hence, out of scope of global ranking (Connelly, 1990). The institution provides the form of title page of doctoral dissertation embosomed with such logo, and often the doctoral supervisors are from the Paris universities. Then the researcher could identify this pattern of academic phenomenon with the capturing name of institutions, Academie de Paris, when rating the institutions by means of blending and adapting, in which the expanded coverage might be feasible for the small institutions, especially in the case of doctoral studies as once shown in the Technical Report III (Boland, 1995; Eaves, 2001). I considered more salient importance from the undergraduate ranking for the US universities -- around 70 percent from the total -- since the essential role will be to educate the general level of intellectuals, and vast in student populace. That is in contrast while graduate ranking shall be made more projected (same percent from the total) in the international universities that often the source of international commonality or sharing -especially if combined with the US universities -- most facile derives from the graduate level of education. The undergraduate education in this frame can be more adequately assumed as subject to the graduate level of student and faculty in the case of international universities. In this way, we finally yield the overall global ranking. Below do we see part of sources from the rankings.

I have made a brief exploration of qualitative method as well as the importance of blending and adapting to generate a deep knowledge of humans and universe. This type of approach could grow and be viewed as more adequate in this post-modern global village, and it would not be unwise that is to be encouraged of this way of research and awareness.

Table 2. A Rating of Global Universities.

\begin{tabular}{l}
\hline A Rating of Global Universities (after Blending and Adapting) \\
\hline 1. Academie de Paris/Princeton University (tied as completed) \\
2. \\
3. \\
4. \\
5. \\
6. \\
7. * For example, Vienna and Cornell can be matched at 7 th or Munich and \\
Caltech may come at 12 th after the qualitative evaluation are to be \\
completed by the interested evaluators/This way can be ahead for the \\
blanks through, as left with them. \\
8. \\
9. \\
10 \\
11 \\
12 \\
13 \\
14 \\
15
\end{tabular}

7 This attribute also corroborates with the national uniformity of research mission as noted with the CNRS and the agencies of socialistic nations.

\begin{tabular}{l}
\hline A Rating of Global Universities (after Blending and Adapting) \\
\hline 16 \\
17 \\
18 \\
19 \\
20 \\
21 \\
22 \\
23 \\
24 \\
25 \\
26 \\
27 \\
28 \\
29 \\
30 \\
$31-100$ \\
\hline
\end{tabular}

For the View of Students around 1996-2003 years

Table 3. A Part of Data: The Gourman Ranking (1997, Princeton Review/same ranking from the Korean guidebook around the 1990's).

\begin{tabular}{|c|c|c|c|}
\hline \multicolumn{2}{|c|}{$\begin{array}{l}\text { A Rating of International } \\
\text { Universities }\end{array}$} & \multicolumn{2}{|c|}{$\begin{array}{l}\text { A Rating of Top } 50 \\
\text { Undergraduate Institutions }\end{array}$} \\
\hline $1(4.92)$ & Academie de Paris & 1. & Princeton \\
\hline $2(4.91)$ & U. of Oxford & 2 & Harvard \\
\hline $3(4.90)$ & U. of Cambridge & 3. & Michigan(Ann Arbor) \\
\hline $4(4.89)$ & U. of Heidelberg & 4. & Yale \\
\hline $5(4.85)$ & $\begin{array}{l}\text { U. of Montpellier } \\
\text { I/II/III }\end{array}$ & 5. & Stanford \\
\hline $6(4.83)$ & U. of Munich & 6. & Calif, Berkeley \\
\hline $7(4.81)$ & U. of Lyons I/II/III & 7. & Cornell \\
\hline $8(4.80)$ & U. of Lillie I/II/III & 8. & Chicago \\
\hline $9(4.79)$ & U. of Edinburgh & 9. & Wis. (Madison) \\
\hline $10(4.77)$ & U. of Vienna & 10. & UCLA \\
\hline $11(4.75)$ & $\begin{array}{l}\text { U. of Aix-Marseilles } \\
\text { I/II/III }\end{array}$ & 11. & MIT \\
\hline $12(4.73)$ & Free U. of Brussels & 12. & CAL TECH \\
\hline $13(4.71)$ & U. of Zurich & 13. & Calif. San Diego \\
\hline $14(4.70)$ & U. of Gottingen & 14. & Northwestern \\
\hline $15(4.68)$ & U. of Bordeaux I/II/III & 15. & Pennsylvania \\
\hline $16(4.65)$ & U. of Nancy I/II & 16. & Columbia \\
\hline $17(4.64)$ & U. of Toronto & 17. & Minn. (Minneapolis) \\
\hline $18(4.61)$ & McGill U. & 18. & Brown \\
\hline $19(4.59)$ & U. of Geneva & 19. & Duke \\
\hline $20(4.56)$ & U. of Tubingen & 20. & Dartmouth \\
\hline $21(4.54)$ & $\begin{array}{l}\text { U. of Erlangen- } \\
\text { Nuremberg }\end{array}$ & 21. & Illinois (Urbana) \\
\hline $22(4.53)$ & U. of Grenoble I/II/III & 22. & Brandeis \\
\hline $23(4.52)$ & U. of Burgundy Djon & 23. & Ind. (Bloomington) \\
\hline $24(4.49)$ & U. of Marburg & 24. & Johns Hopkins \\
\hline $25(4.45)$ & U. of Rennes I/II/III & 25. & Notre Dame \\
\hline $26(4.44)$ & U. of Toulouse I/II/III & 26. & Wash. (Seattle) \\
\hline $27(4.42)$ & $\begin{array}{l}\text { U. of Rouen-Haute- } \\
\text { Normandie }\end{array}$ & 27. & Rice \\
\hline $28(4.41)$ & $\begin{array}{l}\text { U. of Clermont- } \\
\text { Ferrand I }\end{array}$ & 28. & NC (Chapel Hill) \\
\hline $29(4.36)$ & $\begin{array}{l}\text { U. of Friedrich- } \\
\text { Wilhelm }\end{array}$ & 29. & NYU \\
\hline $30(4.35)$ & U. of Bonn & 30. & SUNY (Buffalo) \\
\hline $30(4.35)$ & U. of Cologne & 31. & IOWA (Iowa City) \\
\hline $31(4.33)$ & U. of Nice & 32. & Calif. Davis \\
\hline $32(4.32)$ & $\begin{array}{l}\text { Hebrew U. of } \\
\text { Jerusalem }\end{array}$ & 33. & Texas (Austin) \\
\hline $33(4.30)$ & Johann Wolfgang & 34. & OHIO State(Columbus) \\
\hline
\end{tabular}




\begin{tabular}{|c|c|c|c|}
\hline \multicolumn{2}{|c|}{$\begin{array}{l}\text { A Rating of International } \\
\text { Universities }\end{array}$} & \multicolumn{2}{|c|}{$\begin{array}{l}\text { A Rating of Top } 50 \\
\text { Undergraduate Institutions }\end{array}$} \\
\hline & Goethe & & \\
\hline $33(4.30)$ & U. of Frankfurt & 35. & Carnegie-Mellon \\
\hline $34(4.24)$ & Catholic U. of Louvain & 36. & Calif. Irvine \\
\hline $35(4.20)$ & Stockholm U. & 37. & $\begin{array}{l}\text { Penn State (University } \\
\text { Park) }\end{array}$ \\
\hline $36(4.17)$ & U. of Munster & 38. & Calif. Santa Barbara \\
\hline $37(4.16)$ & U. of Copenhagen & 39. & Vanderbilt \\
\hline $38(4.15)$ & $\begin{array}{l}\text { J. Gutenberg U. of } \\
\text { Mainz }\end{array}$ & 40. & Rochester \\
\hline $39(4.14)$ & U. of Wurzburg & 41. & Virginia \\
\hline $40(4.13)$ & $\begin{array}{l}\text { U. of Franche-Comte } \\
\text { Besancon }\end{array}$ & 42. & Georgia Tech \\
\hline $41(4.12)$ & U. of Amsterdam & 43. & Michigan State \\
\hline $42(4.11)$ & U. of London & 44. & Purdue (Lafayette) \\
\hline $43(4.10)$ & U. of Tokyo & 45. & Tufts \\
\hline $44(4.09)$ & U. of Nantes & 46. & $\begin{array}{l}\text { Rutgers (New } \\
\text { Brunswick) }\end{array}$ \\
\hline $45(4.08)$ & U. of Poitiers & 47. & SUNY (Stony Brook) \\
\hline $46(4.07)$ & U. of Orleans & 48. & Tulane \\
\hline $47(4.05)$ & U. of Caen & 49. & Washington (St. Louis) \\
\hline $48(4.04)$ & U. of Bologna & 50. & R.P.I. \\
\hline $49(4.03)$ & U. of Madrid & & \\
\hline
\end{tabular}

Very Strong $=4.51-4.99$ Strong $=4.01-4.49 \mathrm{Good}=3.61-3.99$ Acceptable Plus $=3.01-3.59$ Adequate $=2.51-2.99$ Marginal $=2.01-2.49$

\section{References}

[1] Armstrong, D., Gosling, A., Weinman, J. \& Marteau, T. (1997) The place of interrater reliability in qualitative research: An empirical study. Sociology, 31, 597-606.

[2] Atkinson, P., Coffey, A., \& Delamont, S. (2003). Key themes in qualitative research: continuities and changes. Walnut Creek, CA: AltaMira.

[3] Bloland, H. G. (1995). Postmodernism and higher education. Journal of Higher Education, 66, 521-559.

[4] Carter, K. (1993). The place of a story in the study of teaching and teacher education. Educational Researcher, 22, 5-12, 18.

[5] Clifford, J., \& Marcus, G. E. (Eds.). (1986). Writing culture: The poetics and politics of ethnography. Berkeley: University of California Press.

[6] Connelly, F. M., \& Clandinin, D. J. (1990). Stories of experience and narrative inquiry. Educational Researcher, 19(5), 2-14.

[7] Creswell, J.W. (2009), Research design :Qualitative, quantitative, and mixed approach, (Laureate Education, Inc., custom ed.). Thousand Oaks, CA: SAGE

[8] Creswell, J. W. (2013). Qualitative inquiry and research design: Choosing among five approaches (3rd ed.). Thousand Oaks, CA: Sage Publications, Inc.

[9] Eaves, YD (2001). A synthesis technique for grounded theory data analysis. J. Adv. Nurs. 35(5), 654-63.

[10] Gay, G. (2000). Culturally responsive teaching: Theory, research, \& practice. New York: Teachers College Press.

[11] Gergen, K. (1994). Realities and relationships: Soundings in social construction. Cambridge, MA: Harvard University Press.
[12] Giddens, A. 1991. Modernity and self-identity: Self and society in the late modern age. Stanford, CA: Stanford University Press.

[13] Guba, E. G., \& Lincoln, Y. S. (1989). Fourth generation evaluation. Newbury Park, CA: Sage.

[14] Hashemi, S.H., Dastani, H. Sadri, J. (2013). A new data analysis technique to examine crack tip opening angle values tested in API X65 pipe steel. Retrieved July 28, 2015 from https://www.researchgate.net/publication/264636060_A_new data_analysis_technique_to_examine_crack_tip_opening_angl e_values_tested_in_API_X 65 _pipe_steel.

[15] Hatch, J. A. (2002). Doing qualitative research in education settings. Albany: State University of New York Press.

[16] Heinze, A. (2008). Blended learning: An interpretive action research study. Retrieved Aug. 11, 2015 from http://usir.salford.ac.uk/1653/1/Heinze_2008 blended_elearning.pdf.

[17] Henry, T. 1989. Break all rules! Punk rock and the making of a style. Ann Arbor: University of Michigan Research Press.

[18] Holmes, U.T. (1962). Daily living in the twelfth century, Madison. WI: University of Wisconsin Press.

[19] Huber, J., \& Whelan, K. (1999). A marginal story as a place of possibility: Negotiating self on the professional knowledge landscape. Teaching and Teacher Education, 15, 381-396.

[20] Hurteau, M., Houle, S., \& Mongiat, S. (2009). "How Legitimate and Justified are Judgments in Program Evaluation?". Evaluation 15 (3): 307-319. doi: $10.1177 / 1356389009105883$.

[21] Husserl, E. (1931). Ideas: General introduction to pure phenomenology (D. Carr, Trans.). Evanston, IL: Northwestern University Press.

[22] Husserl, E. (1970). The crisis of European sciences and transcendental phenomenology (D. Carr, Trans.). Evanston, IL: Northwestern University Press.

[23] JHSPH OPEN COURSEWARE. Qualitative Data Analysis. Retrieved July, 29, 2015 from http://ocw.jhsph.edu/index.cfm/go/viewCourse/course/Qualitat iveDataAnalysis/coursePage/index/.

[24] Kim, K., Concerning the Research and Science (April 10, 2015). Available at SSRN: http://ssrn.com/abstract $=2592858$ or http://dx.doi.org/10.2139/ssrn.2592858.

[25] Kim, K., Some Temperance on the Doctoral Studies and OnLine Education (April 3, 2015). Available at SSRN: http://ssrn.com/abstract=2589531 http://dx.doi.org/10.2139/ssrn.2589531.

[26] Koro-Ljungberg, M., \& Greckhamer, T. (2005). Strategic turns labeled "ethnography": From description to openly ideological production of cultures. Qualitative Research, 5(3), 285-306.

[27] Kvale, S. (2006). Dominance through interviews and dialogues. Qualitative Inquiry, 12, 480-500.

[28] Laureate Education, Inc. (2008). Research theory, design, and methods. Baltimore, MD: Author. "Doctoral Research: Social Change."

[29] Marty, M. E., and R. S. Appleby, (eds.) (1993). Fundamentalism and the state. Chicago: University of Chicago Press. 
[30] Mills, W. C. (1959). The sociological imagination. New York: Oxford University Press.

[31] Merrill et al (2000). Qualitative Data Analysis Chapter 10, Retrieved from July 28, 2015 from http://www.sagepub.com/sites/default/files/upmbinaries/43454_10.pdf.

[32] National Academy of Sciences. (2000). Scientific research in education. Washington, DC: National Research Council.

[33] Onwuegbuzie, A.J., Leech, N.L., Collins, K.M.T. (2012). Qualitative Analysis Techniques for the Review of the Literature The Qualitative Report 2012, Vol. 17, Art. 56, 1-28. Retrieved http://www.nova.edu/ssss/QR/QR17/onwuegbuzie.pdf.

[34] Parson, T., (2009). The role of theory in social research. American Sociological Review, 3(1), pp.13-20.

[35] Patton, M.Q. (1999). Enhancing the quality and credibility of qualitative analysis. Health Serv. Res. 1999 Dec; 34(5 Pt 2): 1189-1208.

[36] Patton, M. Q. (2002). Qualitative research and evaluation methods (3rd ed.). Thousand Oaks, CA: Sage Publications, Inc.
[37] Ratcliff, D. (2015). Methods of Data Analysis in Qualitative Research. Retrieved July 28, 2015 from https://connect.ssri.duke.edu/sites/connect.ssri.duke.edu/files/ upload/help-

resource/Ratcliff. $15 \% 20$ methods $\% 20$ of $\% 20$ qualitative $\% 20$ dat a\%20analysis.pdf.

[38] Reynold, P. D. (2007). A primer in theory construction. Boston, MA: Allyn \& Bacon.

[39] Rosenau, P. M. (1992). Post-modernism and the social sciences: Insights, inroads, and intrusions. Princeton, NJ: Princeton University Press.

[40] Saldaña, J. (2011). Fundamentals of qualitative research. Oxford: Oxford University Press.

[41] Scott, J. 1985. Weapons of the weak: Everyday forms of peasant resistance. New Haven, CT: Yale University Press.

[42] Sanjek, R. (1990). Fieldnotes: The makings of anthropology. Ithaca, NY: Cornell University Press.

[43] Strauss, A. (1987). Qualitative analysis for social scientists. New York: Cambridge University Press. 